\title{
Comment on "Performance of ANFIS versus MLP-NN dissolved oxygen prediction models in water quality monitoring A. Najah \& A. El-Shafie \& O. A. Karim \& Amr H. El-Shafie. Environ Sci Pollut Res (2014) 21:1658-1670"
}

\author{
Salim Heddam
}

Received: 14 July 2014 / Accepted: 3 November 2014 / Published online: 14 November 2014

(C) Springer-Verlag Berlin Heidelberg 2014

The title of Fig. 3 is "Optimal architecture of ANN and flowchart of algorithm procedure." This is a detailed description of the ANFIS model (also stated by the authors at the beginning of page 1662 on the right side that the optimal ANFIS model and a flowchart of the algorithm's procedure are illustrated in Fig. 3). The word "ANN" should be replaced by the word "ANFIS."

Responsible editor: Philippe Garrigues

S. Heddam $(\bowtie)$

Faculty of Science, Agronomy Department, Hydraulics Division

University, 20 Août 1955, Route El Hadaik, BP 26, Skikda, Algeria

e-mail: heddamsalim@yahoo.fr 